\title{
Age-associated differences in transporter gene expression in kidneys of male rats
}

\author{
YONG-JI XU, YANG WANG, YUAN-FU LU, SHANG-FU XU, QIN WU and JIE LIU \\ Key Lab for Pharmacology of Ministry of Education, Zunyi Medical College, Zunyi, Guizhou 563000, P.R. China
}

Received December 2, 2015; Accepted October 18, 2016

DOI: $10.3892 / \mathrm{mmr} .2016 .5970$

\begin{abstract}
Kidney transporters are involved in the secretion and reabsorption of endogenous and exogenous molecules. Numerous factors may influence their expression and affect drug disposition, efficacy and toxicity. The present study aimed to examine the development- and age-associated variations in primary renal transporters in rats, including 6 uptake transporters: Organic anion transporter (OAT) 1 and 3, organic cation transporter (OCT) 1, 2 and 3 and organic anion-transporting polypeptide (OATP) 4C1, and 6 efflux transporters: Multidrug resistance protein 1 (MDR1), breast cancer resistance protein (BCRP), multidrug resistance-associated protein (MRP) 2 and 4, and multidrug and toxin extrusion protein (MATE) 1 and 2-K. Kidneys from male Sprague Dawley rats during development (-2, 1, 7, 14 and 21 days), maturation $(28,35$ and 60 days) and aging (180, 540 and 850 days) were collected and total RNA was extracted, purified and subjected to reverse transcription-quantitative polymerase chain reaction analysis. Total proteins were extracted for western blot analysis. OAT1 and 3, OCT1, BCRP, MRP2 and 4 and MATE2-K expression levels were low in fetal kidneys, increased gradually following birth and markedly increased on maturation and adulthood. High levels were maintained until 850 days. OCT2, OATP4C1, Mdrlb and MATE1 expression levels were low in fetal kidneys, increased gradually following birth, and increased markedly on weaning, maturation and adulthood; however, levels were decreased on aging. OCT3 mRNA expression levels were low in fetal and newborn kidneys, and had two peaks at 35 and
\end{abstract}

Correspondence to: Dr Yuan-Fu Lu or Dr Jie Liu, Key Lab for Pharmacology of Ministry of Education, Zunyi Medical College, 201 Dalian Road, Zunyi, Guizhou 563000, P.R. China

E-mail: yflu@zmc.edu.cn

E-mail: jie@liuonline.com

Abbreviations: BCRP, breast cancer resistance protein; MATE, multidrug and toxin extrusion protein; Mdrlb, multidrug resistance protein 1b; MRP, multidrug resistance-associated protein; OAT, organic anion transporter; OATP, organic anion-transporting polypeptide; OCT, organic cation transporter; RT-qPCR, reverse transcription-quantitative polymerase chain reaction

Key words: kidney, transporter, ontogeny, aging, rats
850 days. The selected OAT1 and 3 and MDR1 protein expression levels revealed a similar expression pattern. Thus, kidney transporter expression is affected by ontogeny and aging, which may impact drug and toxicant disposition in children and the elderly.

\section{Introduction}

The kidneys are crucial for the elimination of endogenous metabolites and xenobiotics, including drugs and environmental chemicals. At least 37 xenobiotic transporters have been identified in mammalian kidneys (1). Transporter proteins provide organ/tissue defense and are involved in the therapeutic effects and toxicity of numerous drugs and toxicants (2-4). Important basolateral uptake transporters include organic anion transporter (OAT) 1, 2 and 3, organic cation transporter (OCT) 1, 2 and 3 and organic anion transporting polypeptide (OATP4C1). Important efflux transporters on the apical brush-border membrane primarily include multidrug resistance protein [P-glycoprotein, encoded by multidrug resistance protein gene lb (Mdrlb)], multidrug resistance-associated protein (MRP) 2 and 4, multidrug and toxin extrusion protein (MATE) 1 and 2 and breast cancer resistance protein (BCRP) $(2,5,6)$.

Renal OATs are important in the uptake of common drugs, toxins and nutrients $(3,7)$. For example, OAT1 and 3 are critical for renal mercury absorption and accumulation from inorganic $(3,8,9)$ or organic mercury $(10)$. Deletion of OAT1 and 3 protects against nephrotoxicity induced by mercury chloride (11) and aristolochic acid I (12). Thus, alterations of OAT1 and 3 greatly impact chemical-induced nephrotoxicity (13).

In addition, renal OCTs are important in transporting cationic xeno- and endobiotics across biological membranes. For example, OCT1 and 2 mediate the renal uptake and accumulation of platinum compounds (14) and cadmium (15); modification of OCT expression levels causes altered proximal tubular cell accumulation of cisplatin and cadmium, resulting in decreased or increased toxicity (14-16).

Mdr1 and MRP2 are expressed in proximal tubular epithelial cells and are crucial for protection against toxicant-induced kidney injury. For example, Mdr1 protects against paraquat-induced toxicity in human and murine proximal tubular cells (17), while MRP2 protects against mercury-induced kidney injury $(18,19)$.

MATE1 and 2 mediate cisplatin-induced nephrotoxicity via a reduction in cellular efflux (16). MATE and OCT2 affect 
cisplatin accumulation and toxicity in coordination (20). The efflux transporter BCRP is involved in the elimination of mercury from proximal tubular cells (6).

The expression of renal transporters may be affected by drugs and toxicants, and by physiological variations. For example, females express reduced levels of renal OAT1 and 3, and are therefore less susceptible to mercury-induced kidney injury (21). Older rats are more susceptible to mercury nephrotoxicity compared with younger rats (22), and methylmercury may cross the placenta to the fetus, resulting in accumulation and toxicity (19). Thus, understanding the ontogeny and aging-associated alterations in renal transporter expression is important for the evaluation of drug or toxicants effects in sensitive populations. For this reason, the ontogeny of the expression of renal transporters, including OCTs (23), MATE1 and 2 (24) and OATs (1) has been investigated in mice. However, in rats the majority of studies have examined the expression of OATs (25-27).

Recently, the whitepaper of Pediatric Transporter Working Group presented a systematic review of the ontogeny of clinically relevant transporters in intestine, liver and kidney (4). Different developmental patterns for individual transporters exist; however, these remain to be fully elucidated, particularly with regard to elderly populations. The present study aimed to address this. Kidneys were collected from male Sprague Dawley rats at 11 time points: Fetal (-2 days), birth (1 day), nursing (7 and 14 days), weaning (21 days), puberty (28 and 35 days), maturation (60 days), adulthood (180 days) and aging (540 and 850 days). The mRNA expression levels of six primary renal uptake transporters (OAT1 and 3, OATP4C1, and OCT1, 2 and 3) and six primary efflux transporters (Mdr1b, MRP2 and 4, MATE1 and 2, and BCRP) were examined, and three selected transporters (OAT1 and 3, and MDR1) were additionally examined at the protein levels via western blot analysis. The results obtained may be of physiological, pharmacological and toxicological significance.

\section{Materials and methods}

Animals. Sprague Dawley rats (weight, 250-300 g; 10 male, 30 female as parents of the experimental mice) were purchased from the Experimental Animal Center of Third Military Medical College (Chongqing, China) and acclimatized for one week prior to mating overnight. Rats were housed in specific pathogen-free-grade animal facilities under a 12-h light/dark cycle, at $22 \pm 2^{\circ} \mathrm{C}$ and $50 \%$ humidity, and had access to feed and water ad libitum. All animal procedures experiments were performed in accordance with Chinese Guidelines of Animal Care and Welfare, and the present study was approved by the Animal Care and Use Committee of Zunyi Medical College (Zunyi, China).

Tissue collection. If a vaginal plug was present the next morning this was designated as day 0 of gestation. Kidneys were collected from male rats only at developmental days -2 , $1,7,14,21,28,35$ and 60 and ageing days 180, 540 and 850, where day 0 was the day of birth. Rats were anesthetized with $7 \%$ chloral hydrate $(5 \mathrm{ml} / \mathrm{kg})$, sacrificed by cervical dislocation, and kidneys were frozen in liquid nitrogen and stored at $-80^{\circ} \mathrm{C}$ prior to analysis.
RNA isolation. Kidney tissue (50-100 mg) was homogenized in $1 \mathrm{ml} \mathrm{TRIzol}{ }^{\circledR}$ (Takara Biotechnology Co., Ltd., Dalian, China). The quality and quantity of RNA were determined by measuring the absorbance at wavelengths of 260 and $280 \mathrm{~nm}$ and calculating the 260/280 ratio, and by gel electrophoresis.

Reverse transcription-quantitative polymerase chain reaction $(R T-q P C R)$. Total RNA was reverse transcribed with the High Capacity Reverse Transcriptase kit (Applied Biosystems; Thermo Fisher Scientific, Inc.). The $\mathrm{iQ}^{\mathrm{TM}} \mathrm{SYBR}^{\circledR}$ Green Supermix (Bio-Rad Laboratories, Inc., Hercules, CA, USA) was used for qPCR analysis. The primers were designed with Primer3 software (version 4.0) and are listed in Table I. The $15 \mu \mathrm{l}$ PCR reaction mix contained $3 \mu \mathrm{l}$ cDNA (10 ng/ $\mu \mathrm{l}$ ), $7.5 \mu 1$ iQTM SYBR Green Supermix (Bio-Rad Laboratories, Inc.), $0.5 \mu \mathrm{l}$ primer mix (10 $\mu \mathrm{M}$ each), and $4 \mu \mathrm{lddH} 2 \mathrm{O}$. The thermocycling conditions were as follows: 5 min denaturation at $95^{\circ} \mathrm{C} ; 40$ cycles of annealing and extension at $60^{\circ} \mathrm{C}$ for $45 \mathrm{sec}$, and denaturation at $95^{\circ} \mathrm{C}$ for $10 \mathrm{sec}$. A dissociation curve was performed following the 40 cycles to verify the quality of primers and amplification. Relative expression of genes was calculated by the $2^{-\Delta \Delta \mathrm{Cq}}$ method (28), and normalized to the housekeeping gene GAPDH and $\beta$-actin of the same sample, and the relative transcript levels were calculated as percentage of -2 days.

Protein extraction and quantification. Kidneys from each group were pooled and $100 \mathrm{mg}$ was homogenized in $1 \mathrm{ml}$ radioimmunoprecipitation assay lysis buffer (Beyotime Institute of Biotechnology, Shanghai, China) containing $1 \mathrm{mM}$ phenylmethanesulfonyl fluoride and proteinase inhibitors. The lysates were centrifuged at $12,000 \mathrm{x}$ for $10 \mathrm{~min}$ at $4^{\circ} \mathrm{C}$, and supernatants were collected and stored at $-80^{\circ} \mathrm{C}$ prior to analysis. Protein concentrations were quantified by the Bicinchoninic Acid assay (Beyotime Institute of Biotechnology).

Western blot analysis. Aliquoted proteins were denatured with loading buffer (catalog no. P0015; Beyotime Institute of Biotechnology) at $90^{\circ} \mathrm{C}$ for $10 \mathrm{~min}$, and $\sim 10 \mu \mathrm{g}$ protein/lane was separated on $10 \%$ SDS-PAGE gels and transferred to polyvinylidene difluoride membranes. Membranes were blocked with 5\% dry non-fat milk in TBS containing $0.07 \%$ Tween-20 (TBST) at room temperature for $2 \mathrm{~h}$, followed by incubation overnight at $4^{\circ} \mathrm{C}$ with the following primary antibodies, diluted $1: 1,000$ in $1 \%$ bovine serum albumin (Sigma-Aldrich; Merck Millipore, Darmstadt, Germany) in TBST. Antibodies were Goat anti-OAT1 (cat.no. sc-161977; Santa Cruz Biotechnology, Inc., Dallas, TX, USA), goat anti-OAT3 (cat. no. sc-107836; Santa Cruz Biotechnology, Inc.), rabbit anti-MDR1 (cat. no. ab170904; Abcam, Cambridge, UK) and mouse anti- $\beta$-actin (cat. no. AA128-1; Beyotime Institute of Biotechnology). Following three washes with TBST, membranes were incubated with horseradish peroxidase-conjugated anti-rabbit (cat. no. A0208), anti-mouse (cat. no. A0126), or anti-goat (cat. no. A0181) IgG secondary antibodies, all obtained from Beyotime Institute of Biotechnology) and used at a dilution of 1:5,000 for $1 \mathrm{~h}$ at room temperature. Protein-antibody complexes were visualized using an Enhanced Chemiluminescent reagent (catalog no. P0018; 
Table I. Primer sequences used in reverse transcription-quantitative polymerase chain reaction analysis.

\begin{tabular}{|c|c|c|c|}
\hline \multirow[b]{2}{*}{ Gene } & \multirow[b]{2}{*}{ GenBank no. } & \multicolumn{2}{|c|}{ Sequence $\left(5^{\prime}-3^{\prime}\right)$} \\
\hline & & Forward & Reverse \\
\hline$\beta$-actin & NM_007393 & catccgtaaagacctctatgccaac & atggagccaccgatccaca \\
\hline OAT1 & NM_017224 & cttgtacaccggagagc & aggcatggaggggtagaact \\
\hline OAT3 & NM_031332 & gttgacatcccagccaagtt & ctgcatttctgaaggcacaa \\
\hline OCT1 & U17013 & agcagctcaccaatcaaagc & gtggagtctgtagtgcctgt \\
\hline OCT2 & NM_031584 & ttgtctgctcctccatgtgt & agagccttccetttggtctc \\
\hline ОСТ3 & NM_031332 & gtctctctctggcetggttt & gcacaaagatgagggccaaa \\
\hline OATP4C1 & NM_001002024 & tcaagctggcaaaacttccc & ccgcaaagctcgatgtcaat \\
\hline MRP2 & NM_012833 & tctcttgcgctcacagaaga & gaaactggaatacgccgcat \\
\hline MRP4 & AY533524 & accaggatgccgacatctac & cgtgcaaagtgtggcagata \\
\hline BCRP & NM_181381 & ccagcetcggtattccatct & cagccgaagaatctccgttg \\
\hline MATE1 & NM_001014118 & cctgagtggtatccttggca & ggcctggtcaatgtttcctg \\
\hline MATE2-K & NM_001191920 & cacctcccagttcttcctgt & tcccaatctcgaaggtccac \\
\hline Mdr1b & NM_012623 & tgtttgactgcagcatcacc & agctgagtccetttgtctcc \\
\hline
\end{tabular}

OAT, organic anion transporter; OCT, organic cation transporter; OATP, organic anion-transporting polypeptide; MRP, multidrug resistance-associated protein; BCRP, breast cancer resistance protein; MATE, multidrug and toxin extrusion protein; Mdr1b, multidrug resistance protein gene $1 \mathrm{~b}$.

Beyotime Institute of Biotechnology), and a ChemiDoc XRS system (Bio-Rad Laboratories, Inc.). Band intensities were semi-quantified by densitometry using Quantity One ${ }^{\circledR}$ software (version 4.6.2, Bio-Rad Laboratories, Inc.).

Statistical analysis. Statistical analyses were performed in SPSS software version 16.0 (SPSS, Inc., Chicago, IL, USA). Data were expressed as the mean \pm standard error. Age-associated differences were analyzed by one-way analysis of variance, followed by the least significant difference post hoc test. $\mathrm{P}<0.05$ was considered to indicate a statistically significant difference.

\section{Results}

Basolateral uptake transporter expression levels in kidneys. On the basolateral membrane of the kidneys, the primary anion transporters are OAT1 and 3, and OATP4C1; the primary cation transporters are OCT1, 2 and 3.

OAT1 and 3. OAT1 and OAT3 are involved in the active uptake of chemicals and toxicants. The mRNA expression levels of OAT1 and 3 increased significantly with age from -2 to 850 days (Fig. 1). OAT1 mRNA expression levels were low in fetal kidneys, increased gradually following birth and increased markedly on maturation and adulthood (peaking at 180 days). Compared with OAT1 mRNA expression levels at -2 days, OAT1 levels at 180 days were 35 -fold greater, and were maintained at that high level until 850 days (Fig. 1).

OAT3 mRNA expression levels were low in fetal and newborn kidneys; however, these levels increased rapidly following birth and continued to increase during adulthood. Compared with OAT3 mRNA expression levels at birth, OAT3 levels at 180 days were 22-fold greater, and were maintained at that high level and even increased until 850 days (Fig. 1).
The protein expression levels of OAT1 (Fig. 2) and 3 (Fig. 3) followed similar patterns to the mRNA expression levels. OAT1 protein was undetectable at day 1 , reached a peak on maturation, and remained high on aging $(\mathrm{P}<0.05$ vs. -2 days; Fig. 2). OAT3 protein was undetectable at -2 and 1 days; however, protein expression levels subsequently increased throughout weaning, maturation, adulthood and aging $(\mathrm{P}<0.05$ vs. -2 days; Fig. 3).

OCT1, 2 and 3, and OATP4C1. OCTs are responsible for excretion of cationic substances into urine. Tissue OCT expression is important for the disposition and excretion of xenobiotics. On the basolateral membrane of the kidneys, OCT1, 2 and 3 are the primary cation transporters, whereas OATP4C1 is the primary anion transporter. The mRNA expression levels of OCT1, 2 and 3, and OATP4C1 increased significantly with age from -2 to 850 days (Fig. 4).

OCT1 mRNA expression levels were low in fetal kidneys, increased gradually following birth, and increased markedly on weaning, maturation and adulthood (peaking at 540 days). Compared with OCT1 mRNA expression levels at -2 days, OCT1 levels at 420 days were 35 -fold greater, and were maintained at that high level until 850 days ( $\mathrm{P}<0.05$ vs. -2 days; Fig. 4).

Similarly to OCT1, OCT2 mRNA expression levels were low in fetal kidneys, increased gradually following birth, and increased markedly on weaning, maturation and adulthood (peaking at 180 days). Compared with OCT2 mRNA expression levels at -2 days, OCT2 levels at 180 days were 470 -fold greater; however, these levels decreased on aging ( $\mathrm{P}<0.05$ vs. -2 d; Fig. 4).

The ontogeny of OCT3 differed from OCT1 and 2. OCT3 mRNA expression levels were low in fetal and newborn kidneys, increased rapidly following birth and reached a first peak at 35 days. Compared with OCT3 mRNA expression 


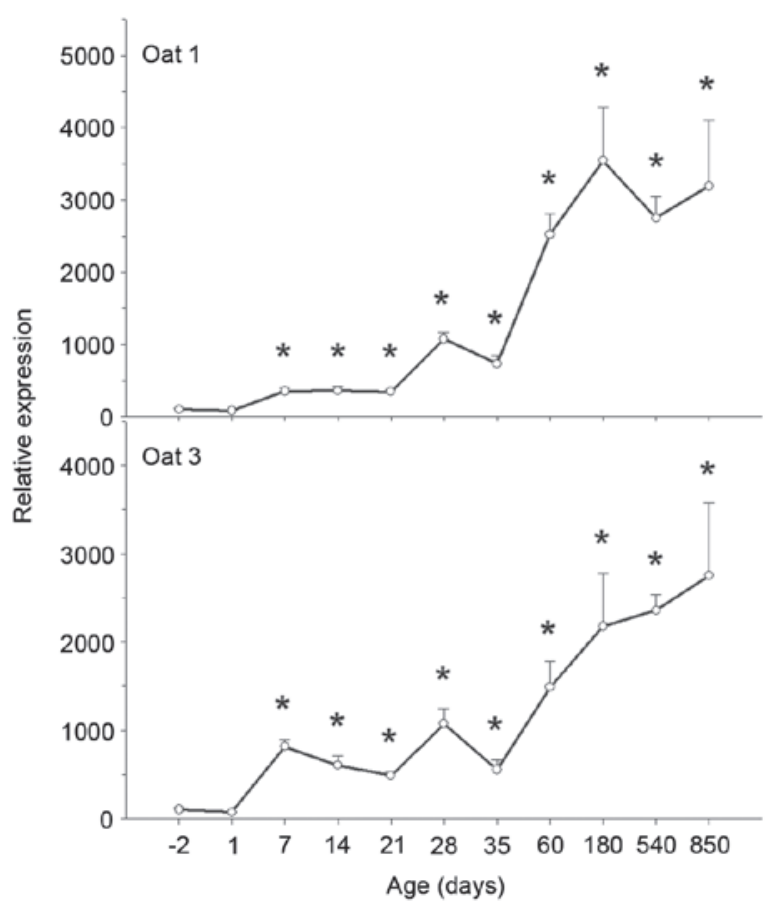

Figure 1. Ontogeny of OAT1 and 3 mRNA expression levels in rat kidney. Kidneys were collected at $-2,1,7,14,21,28,35,60,180,540$ and 850 days, and subjected to reverse transcription-quantitative polymerase chain reaction analysis using specific primers. mRNA expression levels of OAT1 and 3 increased over time. Data are expressed as the mean \pm standard error $(n=6)$. "P $<0.05$ vs. -2 days. OAT, organic anion transporter.

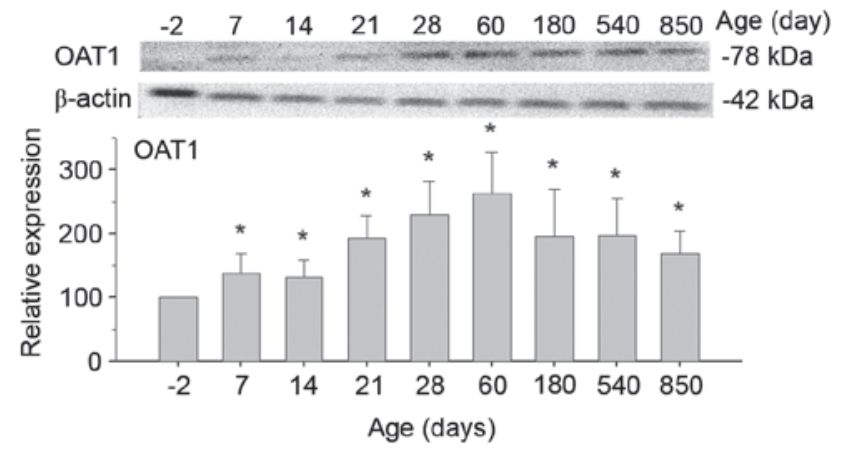

Figure 2. Protein expression levels of OAT1 in rat kidney. Kidneys were collected at $-2,7,14,21,28,60,180,540$ and 850 days, and subjected to western blot analysis using specific antibodies. Protein expression levels of OAT1 increased over time, peaking at 60 days. Data are expressed as the mean \pm standard error of 3-4 replicates of pooled samples. "P<0.05 vs. -2 days. OAT, organic anion transporter.

levels at birth, OCT3 levels at 35 days were 20 -fold greater. Subsequently, OCT3 mRNA expression levels declined, and reached a trough at 180 days. Following this, however, OCT3 mRNA expression levels increased again and reached a second peak at 850 days. Compared with OCT3 mRNA expression levels at birth, OCT3 levels at 850 days were 25 -fold greater ( $\mathrm{P}<0.05$ vs. -2 days; Fig. 4 ).

OATP4C1 mRNA expression levels were low in fetal kidneys, increased gradually following birth, and increased markedly after 14 days, peaking at 180 days. Compared with OATP4C1 mRNA expression levels at -2 days, OATP4C1 levels at 180 days were 35 -fold greater. Subsequently,

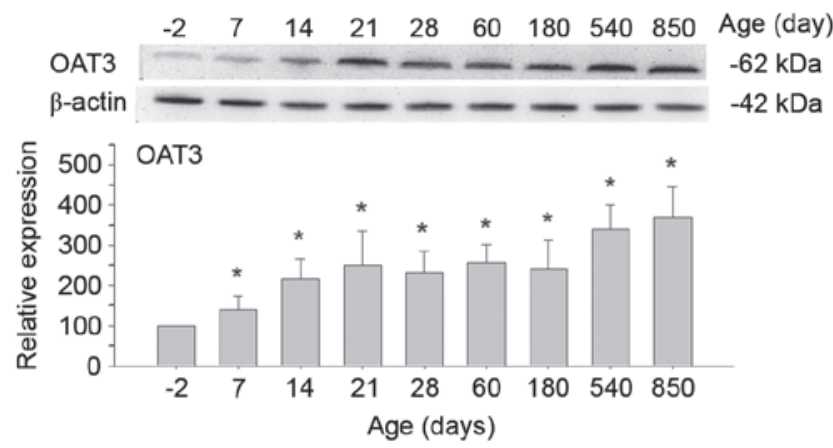

Figure 3. Protein expression levels of OAT3 in rat kidney. Kidneys were collected at $-2,7,14,21,28,60,180,540$ and 850 days, and subjected to western blot analysis using specific antibodies. Protein expression levels of OAT1 increased over time. Data are expressed as the mean \pm standard error of 3-4 replicates of pooled samples. " $\mathrm{P}<0.05$ vs. -2 days. OAT, organic anion transporter.

OATP4C1 mRNA expression levels decreased ( $\mathrm{P}<0.05$ vs. -2 days; Fig. 4).

Apical efflux transporter expression levels in kidneys. The brush-border efflux transporters BCRP, MDR1 MRP2 and 4, and MATE1 and 2-K contribute to the secretion of chemicals from the kidneys into the urine.

BCRP and Mdrlb. BCRP and MDR1 transport an extensive range of endogenous and exogenous lipophilic substrates, including lipids, steroids, peptides and xenobiotics. The mRNA expression levels of BCRP and Mdrlb increased significantly with age from -2 to 850 days (Fig. 5).

BCRP mRNA expression levels were low in fetal and newborn kidneys, and increased rapidly following birth, reaching a peak at 180 days and subsequently declining. Compared with BCRP mRNA expression levels at birth, BCRP levels at 180 days were 18 -fold greater $(\mathrm{P}<0.05$ vs. -2 days; Fig. 5).

Similarly to BCRP, Mdrlb mRNA expression levels were low in fetal kidneys, increased gradually following birth and increased markedly on maturation, peaking at 540 days. Compared with Mdrlb mRNA expression levels at -2 days, Mdr1b levels at 540 days were 23 -fold greater; however, these levels decreased at 850 days (Fig. 5). The protein expression levels of MDR1 followed a similar pattern: Undetectable at 1 day, and increasing on maturation, prior to decreasing at 850 days $(\mathrm{P}<0.05$ vs. -2 days; Fig. 6$)$.

$M R P 2$ and 4. In renal proximal tubules, MRP2 and 4 actively transport numerous organic anions into urine, including drugs and metabolic waste. The mRNA expression levels of MRP2 and 4 increased significantly with age from -2 to 850 days (Fig. 7).

MRP2 mRNA expression levels were reduced $50 \%$ in neonatal kidneys (14 days) compared with fetal kidneys, and subsequently increased markedly following weaning, continuing to increase throughout and peaking at 850 days. Compared with MRP2 mRNA expression levels at -2 days, MRP2 levels at 850 days were 3 -fold greater $(\mathrm{P}<0.05$ vs. -2 days; Fig. 7). 


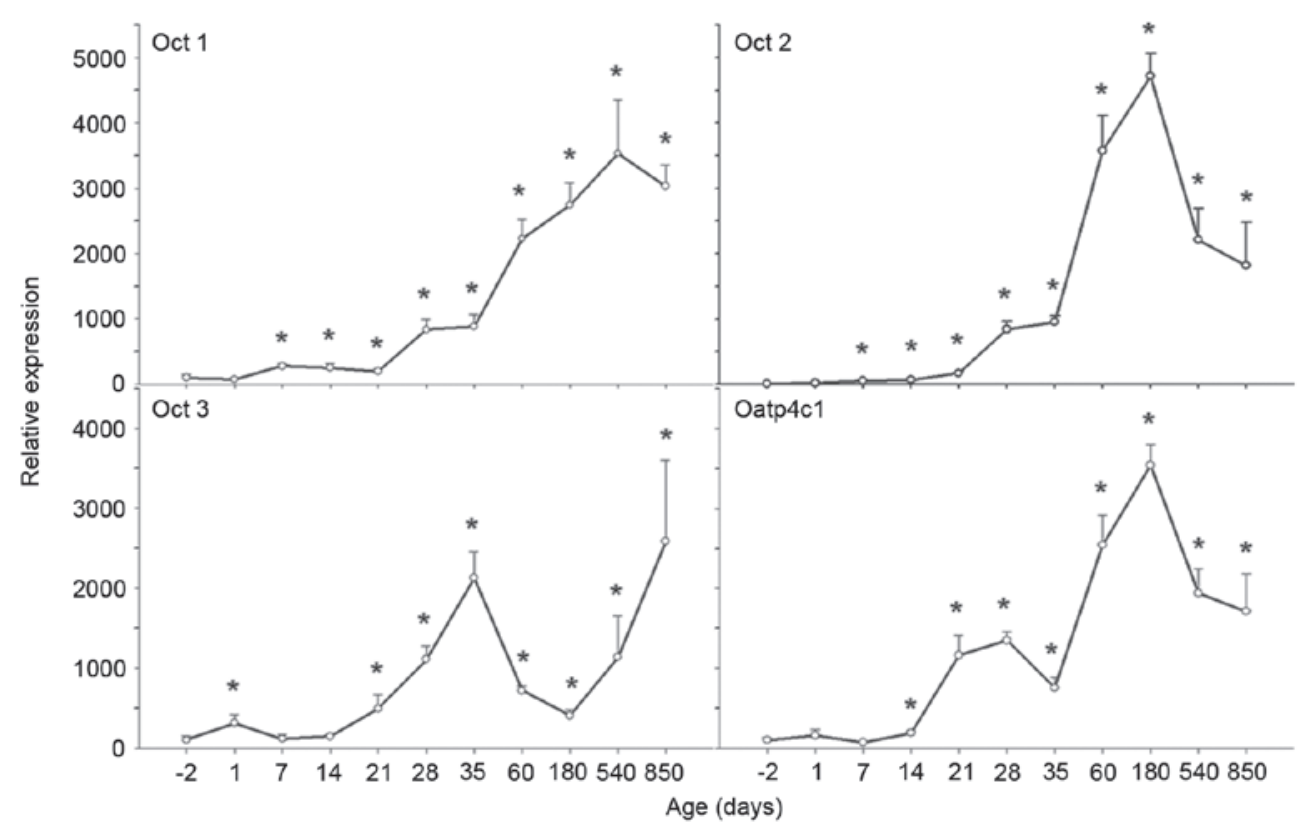

Figure 4. Ontogeny of OCT1, 2 and 3, and OATP4C1 mRNA expression levels in rat kidney. Kidneys were collected at -2, 1, 7, 14, 21, 28, 35, 60, 180, 540 and 850 days, and subjected to reverse transcription-quantitative polymerase chain reaction analysis using specific primers. mRNA expression levels of OCT1 increased over time, levels of OCT2 and OATP4C1 increased over time and subsequently decreased on aging. OCT3 mRNA expression levels exhibited a biphasic pattern. Data are expressed as the mean \pm standard error $(\mathrm{n}=6)$. ${ }^{*} \mathrm{P}<0.05$ vs. -2 days. OCT, organic cation transporter; OATP, organic anion-transporting polypeptide.

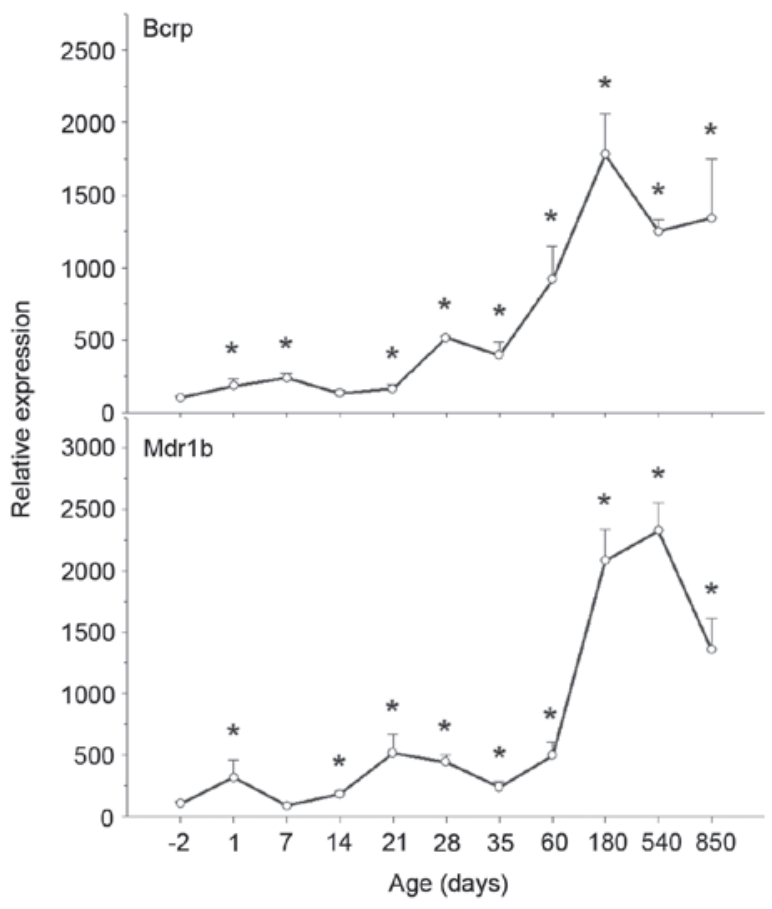

Figure 5. Ontogeny of BCRP and Mdrlb mRNA expression levels in rat kidney. Kidneys were collected at $-2,1,7,14,21,28,35,60,180,540$ and 850 days, and subjected to reverse transcription-quantitative polymerase chain reaction analysis using specific primers. mRNA expression levels of BCRP increased over time, whereas levels of Mdrlb1 increased over time and subsequently decreased on aging. Data are expressed as the mean \pm standard error $(n=6)$. ${ }^{*} \mathrm{P}<0.05$ vs. -2 days. $\mathrm{BCRP}$, breast cancer resistance protein; Mdrlb, multidrug resistance protein gene $1 b$.

MRP4 mRNA expression levels were low in fetal kidneys and increased gradually following birth and through weaning,

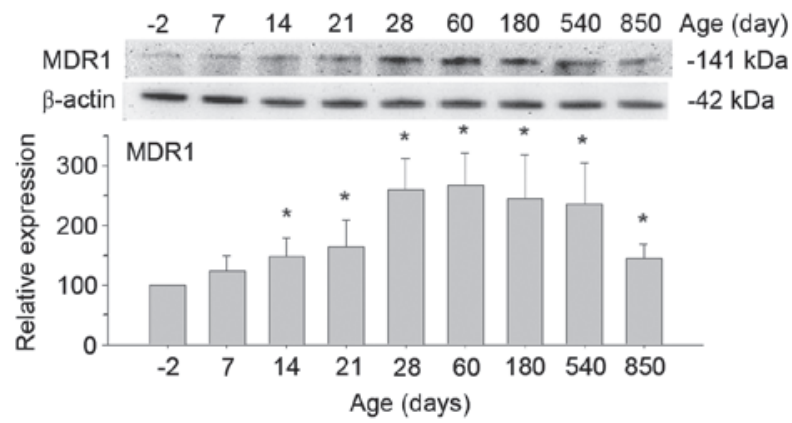

Figure 6. Protein expression levels of MDR1 in rat kidney. Kidneys were collected at $-2,7,14,21,28,60,180,540$ and 850 days, and subjected to western blot analysis using specific antibodies. Protein expression levels of MDR1 increased over time and subsequently decreased on aging. Data are expressed as the mean \pm standard error of 3-4 replicates of pooled samples. ${ }^{*} \mathrm{P}<0.05 \mathrm{vs}$. -2 days. MDR, multidrug resistance.

peaking at 28 days. Compared with the MRP4 mRNA expression levels at -2 days, MRP4 levels at 28 days were 6 -fold greater $(\mathrm{P}<0.05$ vs. -2 days; Fig. 7$)$.

MATE1 and 2-K. The MATE transporters mediate cellular efflux of a variety of organic cations, including numerous drugs. The mRNA expression levels of MATE1 and 2-K increased significantly with age from -2 to 850 days (Fig. 8).

MATE1 mRNA expression levels were low in fetal kidneys, increased gradually following birth, and increased markedly following weaning, peaking at 180 days. Compared with MATE1 mRNA expression levels at -2 days, MATE1 levels at 180 days were 18 -fold greater. MATE1 mRNA expression levels subsequently decreased ( $\mathrm{P}<0.05$ vs. -2 days; Fig. 8 ).

MATE2-K mRNA expression levels were low in fetal kidneys, increased gradually following birth, and increased 


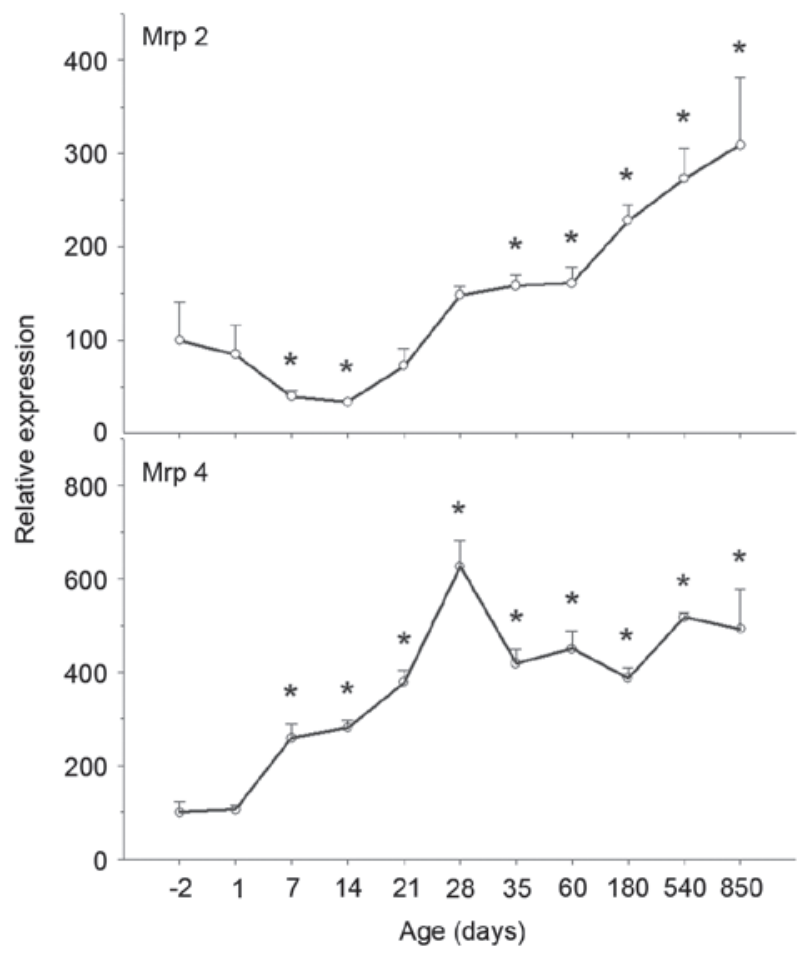

Figure 7. Ontogeny of MRP2 and 4 mRNA expression levels in rat kidney. Kidneys were collected at $-2,1,7,14,21,28,35,60,180,540$ and 850 days, and subjected to reverse transcription-quantitative polymerase chain reaction analysis using specific primers. mRNA expression levels of MRP2 and 4 increased over time. Data are expressed as the mean \pm standard error $(n=6)$. ${ }^{*} \mathrm{P}<0.05$ vs. -2 days. MRP, multidrug resistance-associated protein.

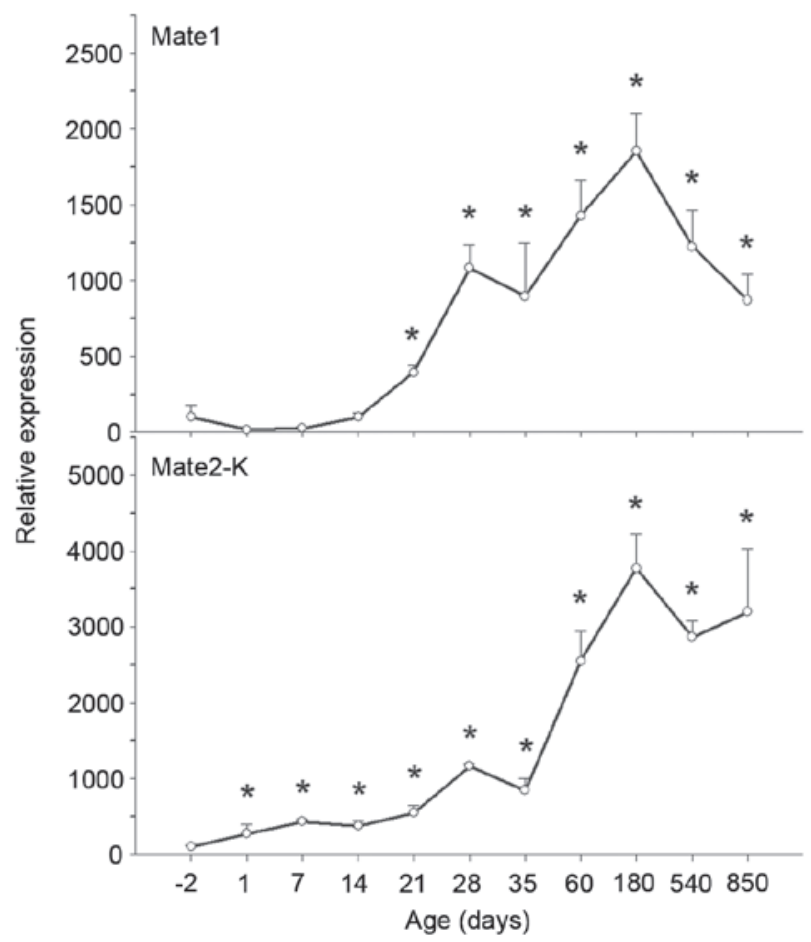

Figure 8. Ontogeny of MATE1 and 2-K mRNA expression levels in rat kidney. Kidneys were collected at -2, 1, 7, 14, 21, 28, 35, 60, 180, 540 and 850 days, and subjected to reverse transcription-quantitative polymerase chain reaction analysis using specific primers. mRNA expression levels of MATE2-K increased over time, whereas levels of MATE1 increased over time and subsequently decreased on aging. Data are expressed as the mean \pm standard error $(n=6)$. $P<0.05$ vs. -2 days. MATE, multidrug and toxin extrusion protein. markedly following maturation, peaking at 180 days. Compared with MATE2-K mRNA expression levels at -2 days, MATE2-K levels at 180 days were 37 -fold greater, and were maintained at that high level on aging $(\mathrm{P}<0.05$ vs. -2 days; Fig. 8).

\section{Discussion}

The present study demonstrated the ontogeny and age-associated variations in 12 primary kidney transporters in rats. These transporters include the transporters responsible for renal uptake of xenobiotics (OAT1 and 3, OCT1, 2 and 3, and OATP4C1) and transporters associated with kidney efflux and excretion of xenobiotics (MDR1, MRP2, MRP4, BCRP and MATE1 and 2-K). Typically, the mRNA expression levels of these transporters were low in fetal kidneys, increased gradually following birth, and increased markedly on maturation and adulthood, maintaining high expression levels on aging. However, the mRNA expression levels of certain transporters, OCT2, OATP4C1, Mdr1b and MATE1 were decreased on aging. The patterns of mRNA and protein expression levels for the three transporters that underwent western blot analysis were similar. The profile of the ontogeny and age-associated expression of these transporters may provide useful information for the disposition of drugs and toxicants in the kidney, similar to our previous study on liver (29). The present study systematically profiled the ontogeny of 12 primary kidney transporters, and to the best of our knowledge, is among the first to profile age-associated variations in transporter expression.

The OAT family has been extensively studied due to its role in the transport of drugs including cisplatin, aristolochic acid and tanshinol $(12,30)$, toxicants including mercury and indoxyl sulfate (13), and nutrients (3,7). OAT expression is markedly altered during renal failure (31). The importance of OAT1 and 3 in $\mathrm{HgCl}_{2}$ and $\mathrm{MeHg}$-induced renal injury has been documented $(8,10,11,32)$. In addition, our recent studies revealed the alterations of OAT1 and 3 in $\mathrm{HgCl}_{2}$-induced acute and subacute renal injury, but not following exposure to $\operatorname{HgS}(33,34)$. The pharmacological modulation of the expression and/or function of OAT1 and 3 may be a potential therapeutic strategy for reducing the nephrotoxicity of $\mathrm{HgCl}_{2}$ (9). The expression of OAT1 and 3 is additionally influenced by gender (21), and the increased expression of OAT1 and 3 in males has been revealed to be regulated by the transcription factor B-cell lymphoma 6 (35). In the kidney, OAT1 transcripts appeared at mid-gestation, alongside proximal tubule differentiation, and increased as nephrons matured (36). The present study demonstrated the ontogeny of OAT expression in the kidney, including during the aging process.

OCTs are important for the disposition and excretion of xenobiotics, including platinum compounds $(14,20)$, cadmium (15,37), metformin (38) and mercury (34). OCT2 and MATEs coordinate to eliminate cationic drugs, including cisplatin, from the kidney $(14,16)$. OCT1 and 2 expression has been demonstrated to be altered during renal failure (31), and OCT mRNA expression levels in kidneys is influenced by age (23). In the present study, OCT1 and 2 revealed a typical ontogeny pattern, whereas OCT3 exhibited a biphasic pattern with peaks at 35 and 850 days, which is in agreement with 
a previous study (25). The age-associated variations in OCT expression may affect the ability of the kidney to process heavy metals and toxicants.

OATP4C1 was identified as a novel uptake transporter primarily expressed at the basolateral membrane of rat kidney proximal tubules. It was hypothesized to act as a vectorial transport partner of an apically-expressed efflux transporter, to enable the translocation of substrates, including uremic toxins $(39,40)$, digoxin and estrone 3 -sulfate (41), and sitagliptin, a therapeutic agent for type 2 diabetes (42), into urine. Numerous factors, including age-associated variation, may influence the expression of OATP4C1, thereby altering drug disposition, efficacy and toxicity (1). Our recent study revealed the ontogeny and age-associated alterations of OATP expression in the liver (29), and in the present study, the ontogeny of OATP4C1, the primary OATP in the kidney, was characterized.

The transporters BCRP and MDR1 belong to the multidrug resistance protein family. BCRP has recently been identified as an additional potential transporter in the elimination of mercury from proximal tubular cells (6), and aristolochic acid I is an additional substrate that is excreted by BCRP (43). The organ- and age-specific expression patterns of these transporters have been demonstrated in adult organs (44). The ontogeny of BCRP in the kidney resembles that of the liver with greater expression in adults (5), and increased expression of BCRP in male rat kidneys was revealed (45). In the present study, the expression levels of BCRP increased with age, and were maintained at high levels until 850 days. Kidney MDR1 is similar to BCRP during development (44). Mdrla and Mdrlb in kidney exhibit increased expression in females due to their inhibition by androgens (46), and Mdrla is important for removing paraquat from kidneys and protecting against its subsequent toxicity (17). MDR1 expression is low at birth, and gradually increases to mature levels at $\sim 30$ days of age (46). In the present study, MDR1 shared a similar development pattern with BCRP; however, MDR1 expression levels were decreased during aging, implying decreased renal excretion function in elderly.

MRP2 and 4 are localized in proximal tubular epithelial cells and actively transport numerous organic anions into urine (47), including $\mathrm{HgCl}_{2}(18,19,48)$ and the immunosuppressant mycophenolic acid (49). In our recent studies, $\mathrm{HgS}$ and $\mathrm{HgS}$-containing traditional medicines differed from $\mathrm{HgCl}_{2}$ and $\mathrm{MeHg}$ as they were unable to increase renal expression of MRP2 and $4(33,34)$. The renal toxicity of $\mathrm{Hg}(2+)$ differs in young adult and aged Wistar rats (22), and this may be partially due to the potential aging-associated expression of MRPs. In kidneys, MRP1 and 5 were expressed at adult levels at birth, whereas MRP2, 3, 4 and 6 expression typically increased with time (50); however, little is known about their expression during the aging process. The present study profiled the ontogeny and aging-associated expression of MRP2 and 4 to address this issue.

In the kidney, MATEs coordinate with OCTs to eliminate organic cations. More than 40 therapeutic agents and various endogenous compounds are known to be substrates or inhibitors of MATEs, including cisplatin, metformin and lamivudine $(51,52)$. The inhibitory potencies of ondansetron on MATE1 and 2-K caused increases in tubular cell accumulation of metformin and cisplatin, with increased renal toxicity $(16,20)$. In rats treated repeatedly with $\mathrm{HgCl}_{2}$, MATE2-K expression was increased in an attempt to eliminate cellular Hg (34). The mRNA expression levels of MATE1 in the kidneys of males and females were similar, with levels increasing gradually from prenatal day -2 to 45 days of age. A gender difference appeared at day 30 (24); however, little is known regarding expression during the aging process. In the present study, MATE1 and 2-K exhibited similar ontogeny patterns, and the levels of mRNA expression remained high throughout adulthood, although MATE1 levels decreased during aging.

In conclusion, the results of the present study characterized the ontogeny and age-associated alterations in six primary renal uptake transporters (OAT1 and 3, OCT1, 2 and 3 , and OATP4C1) and six primary renal efflux transporters (MDR1, BCRP, MRP2 and 4, and MATE1 and 2-K) at the mRNA level, and at the protein level of selected transporters (OAT1 and 3, and MDR1). The results confirmed the ontogeny pattern of certain transporters described in the literature, and is among the first to demonstrate the pattern of their expression during development in fetal (-2 days), neonatal $(1,7,14,21$ and 28 days), mature (35 and 60 days) and older (180, 540 and 850 days) rat kidneys. These data may further understanding of age-dependent variations of drug-drug interactions, and drug efficacy and toxicity.

\section{Acknowledgements}

The present study was supported by the Chinese National Science Foundation (grant nos. 81160415 and 81460632).

\section{References}

1. Cheng $X$ and Klaassen CD: Tissue distribution, ontogeny, and hormonal regulation of xenobiotic transporters in mouse kidneys. Drug Metab Dispos 37: 2178-2185, 2009.

2. Klaassen CD and Aleksunes LM: Xenobiotic, bile acid, and cholesterol transporters: Function and regulation. Pharmacol Rev 62: 1-96, 2010.

3. Sweeney DE, Vallon V, Rieg T, Wu W, Gallegos TF and Nigam SK: Functional maturation of drug transporters in the developing, neonatal, and postnatal kidney. Mol Pharmacol 80: 147-154, 2011.

4. Brouwer KL, Aleksunes LM, Brandys B, Giacoia GP, Knipp G, Lukacova V, Meibohm B, Nigam Sk, Rieder M and De Wildt SN; Pediatric Transporter Working Group: Human ontogeny of drug transporters: Review and recommendations of the pediatric transporter working group. Clin Pharmacol Ther 98: 266-287, 2015.

5. de Zwart L, Scholten M, Monbaliu JG, Annaert PP, Van Houdt JM, Van den Wyngaert I, De Schaepdrijver LM, Bailey GP, Coogan TP, Coussement WC and Mannens GS: The ontogeny of drug metabolizing enzymes and transporters in the rat. Reprod Toxicol 26: 220-230, 2008.

6. Bridges CC, Zalups RK and Joshee L: Toxicological significance of renal Bcrp: Another potential transporter in the elimination of mercuric ions from proximal tubular cells. Toxicol Appl Pharmacol 285: 110-117, 2015.

7. Nigam Sk, Bush Kt, Martovetsky G, Ahn Sy, Liu Hc, Richard E, Bhatnagar $\mathrm{V}$ and $\mathrm{Wu} \mathrm{W}$ : The organic anion transporter (OAT) family: A systems biology perspective. Physiol Rev 95: 83-123, 2015.

8. Lash LH, Hueni SE, Putt DA and Zalups RK: Role of organic anion and amino acid carriers in transport of inorganic mercury in rat renal basolateral membrane vesicles: Influence of compensatory renal growth. Toxicol Sci 88: 630-644, 2005.

9. Di Giusto G, Anzai N, Ruiz ML, Endou H and Torres AM: Expression and function of Oat1 and Oat 3 in rat kidney exposed to mercuric chloride. Arch Toxicol 83: 887-897, 2009. 
10. Zalups RK and Ahmad S: Handling of cysteine S-conjugates of methylmercury in MDCK cells expressing human OAT1. Kidney Int 68: 1684-1699, 2005.

11. Torres AM, Dnyanmote AV, Bush KT, Wu W and Nigam SK: Deletion of multispecific organic anion transporter Oat1/Slc22a6 protects against mercury-induced kidney injury. J Biol Chem 286 : 26391-26395, 2011.

12. Xue X, Gong LK, Maeda K, Luan Y, Qi XM, Sugiyama Y and Ren J: Critical role of organic anion transporters 1 and 3 in kidney accumulation and toxicity of aristolochic acid I. Mol Pharm 8: 2183-2192, 2011.

13. Saito H: Pathophysiological regulation of renal SLC22A organic ion transporters in acute kidney injury: Pharmacological and toxicological implications. Pharmacol Ther 125: 79-91, 2010.

14. Kim HJ, Park DJ, Kim JH, Jeong EY, Jung MH, Kim TH, Yang JI, Lee GW, Chung HJ and Chang SH: Glutamine protects against cisplatin-induced nephrotoxicity by decreasing cisplatin accumulation. J Pharmacol Sci 127: 117-126, 2015.

15. Soodvilai S, Nantavishit J, Muanprasat $C$ and Chatsudthipong V: Renal organic cation transporters mediated cadmium-induced nephrotoxicity. Toxicol Lett 204: 38-42, 2011.

16. Li Q, Guo D, Dong Z, Zhang W, Zhang L, Huang SM, Polli JE and Shu Y: Ondansetron can enhance cisplatin-induced nephrotoxicity via inhibition of multiple toxin and extrusion proteins (MATEs). Toxicol Appl Pharmacol 273: 100-109, 2013.

17. Wen X, Gibson CJ, Yang I, Buckley B, Goedken MJ, Richardson JR and Aleksunes LM: MDR1 transporter protects against paraquat-induced toxicity in human and mouse proximal tubule cells. Toxicol Sci 141: 475-483, 2014.

18. Zalups RK, Joshee L and Bridges CC: Novel Hg2+-induced nephropathy in rats and mice lacking Mrp2: Evidence of axial heterogeneity in the handling of $\mathrm{Hg} 2+$ along the proximal tubule. Toxicol Sci 142: 250-260, 2014.

19. Bridges CC, Joshee L and Zalups RK: Placental and fetal disposition of mercuric ions in rats exposed to methylmercury: Role of Mrp2. Reprod Toxicol 34: 628-634, 2012.

20. Yonezawa A and Inui K: Organic cation transporter OCT/SLC22A and $\mathrm{H}(+) /$ organic cation antiporter MATE/SLC47A are key molecules for nephrotoxicity of platinum agents. Biochem Pharmacol 81: 563-568, 2011.

21. Hazelhoff MH, Bulacio RP and Torres AM: Gender related differences in kidney injury induced by mercury. Int J Mol Sci 13: 10523-10536, 2012.

22. Bridges CC, Joshee L and Zalups RK: Aging and the disposition and toxicity of mercury in rats. Exp Gerontol 53: 31-39, 2014

23. Alnouti Y, Petrick JS and Klaassen CD: Tissue distribution and ontogeny of organic cation transporters in mice. Drug Metab Dispos 34: 477-482, 2006.

24. Lickteig AJ, Cheng X, Augustine LM, Klaassen CD and Cherrington NJ: Tissue distribution, ontogeny and induction of the transporters Multidrug and toxin extrusion (MATE) 1 and MATE2 mRNA expression levels in mice. Life Sci 83: 59-64, 2008

25. Slitt AL, Cherrington NJ, Hartley DP, Leazer TM and Klaassen CD: Tissue distribution and renal developmental changes in rat organic cation transporter mRNA levels. Drug Metab Dispos 30: 212-219, 2002.

26. Buist SC, Cherrington NJ, Choudhuri S, Hartley DP and Klaassen CD: Gender-specific and developmental influences on the expression of rat organic anion transporters. J Pharmacol Exp Ther 301: 145-151, 2002.

27. Nakajima N, Sekine T, Cha SH, Tojo A, Hosoyamada M, Kanai Y, Yan K, Awa S and Endou H: Developmental changes in multispecific organic anion transporter 1 expression in the rat kidney. Kidney Int 57: 1608-1616, 2000.

28. Schmittgen TD and Livak KJ: Analyzing real-time PCR data by the comparative C(T) method. Nat Protoc 3: 1101-1108, 2008.

29. Hou WY, Xu SF, Zhu QN, Lu YF, Cheng XG and Liu J: Age- and sex-related differences of organic anion-transporting polypeptide gene expression in livers of rats. Toxicol Appl Pharmacol 280: 370-377, 2014

30. Jia W, Du F, Liu X, Jiang R, Xu F, Yang J, Li L, Wang F, Olaleye OE, Dong J and Li C: Renal tubular secretion of tanshinol: Molecular mechanisms, impact on its systemic exposure, and propensity for dose-related nephrotoxicity and for renal herb-drug interactions. Drug Metab Dispos 43: 669-678, 2015

31. Komazawa H, Yamaguchi H, Hidaka K, Ogura J, Kobayashi M and Iseki K: Renal uptake of substrates for organic anion transporters Oat1 and Oat3 and organic cation transporters Oct1 and Oct2 is altered in rats with adenine-induced chronic renal failure. J Pharm Sci 102: 1086-1094, 2013.
32. Preising C, Schneider R, Bucher M, Gekle M and Sauvant C: Regulation of expression of renal organic anion transporters OAT1 and OAT3 in a model of ischemia/reperfusion injury. Cell Physiol Biochem 37: 1-13, 2015.

33. Sui Y, Yang H, Tian XZ, Liu J and Shi JZ: Effect of Zhusha Anshen pill, cinnabar, $\mathrm{HgS}, \mathrm{HgCl} 2$ and $\mathrm{MeHg}$ on gene expression of renal transporters in mice. Zhongguo Zhong Yao Za Zhi 40: 506-510, 2015 (In Chinese)

34. Zhu QN, Lu YF, Shi JZ, Wu Q, Zhang F, Shi JS and Liu J: Distinct effect of Wansheng Huafeng Dan containing ardisia crenata on renal transporters, mercury accumulation and Kim-1 expression from mercuric chloride. Zhongguo Zhong Yao Za Zhi 39: 1892-1896, 2014 (In Chinese).

35. Wegner W, Burckhardt BC, Burckhardt G and Henjakovic M: Male-dominant activation of rat renal organic anion transporter 1 (Oat1) and 3 (Oat3) expression by transcription factor BCL6. PloS One 7: e35556, 2012

36. Pavlova A, Sakurai H, Leclercq B, Beier DR, Yu AS and Nigam SK: Developmentally regulated expression of organic ion transporters NKT (OAT1), OCT1, NLT (OAT2) and Roct. Am J Physiol Renal Physiol 278: F635-F643, 2000.

37. Ljubojevic M, Breljak D, Herak-Kramberger CM, Anzai N and Sabolić I: Expression of basolateral organic anion and cation transporters in experimental cadmium nephrotoxicity in rat kidney. Arch Toxicol 90: 525-541, 2016.

38. Tzvetkov MV, Vormfelde SV, Balen D, Meineke I, Schmidt T, Sehrt D, Sabolić I, Koepsell H and Brockmöller J: The effects of genetic polymorphisms in the organic cation transporters OCT1, OCT2, and OCT3 on the renal clearance of metformin. Clin Pharmacol Ther 86: 299-306, 2009.

39. Kuo KL, Zhu H, McNamara PJ and Leggas M: Localization and functional characterization of the rat Oatp4c1 transporter in an in vitro cell system and rat tissues. PLos One 7: e39641, 2012.

40. Masereeuw R, Mutsaers HA, Toyohara T, Abe T, Jhawar S, Sweet DH and Lowenstein J: The kidney and uremic toxin removal: Glomerulus or tubule? Semin Nephrol 34: 191-208, 2014.

41. Yamaguchi H, Sugie M, Okada M, Mikkaichi T, Toyohara T, Abe T, Goto J, Hishinuma T, Shimada M and Mano N: Transport of estrone 3-sulfate mediated by organic anion transporter OATP4C1: Estrone 3-sulfate binds to the different recognition site for digoxin in OATP4C1. Drug Metab Pharmacokinet 25: 314-317, 2010.

42. Chu XY, Bleasby K, Yabut J, Cai X, Chan GH, Hafey MJ, Xu S, Bergman AJ, Braun MP, Dean DC and Evers R: Transport of the dipeptidyl peptidase-4 inhibitor sitagliptin by human organic anion transporter 3 , organic anion transporting polypeptide 4C1 and multidrug resistance P-glycoprotein. J Pharmacol Exp Ther 321: 673-683, 2007.

43. Ma L, Qin Y, Shen Z, Bi H, Hu H, Huang M, Zhou H, Yu L, Jiang $\mathrm{H}$ and Zeng S: Aristolochic acid I is a substrate of BCRP but not P-glycoprotein or MRP2. J Ethnopharmacol 172: 430-435, 2015 .

44. Konieczna A, Erdösová B, Lichnovská R, Jandl M, Cizkova K and Ehrmann J: Differential expression of $A B C$ transporters (MDR1, MRP1, BCRP) in developing human embryos. J Mol Histol 42: 567-574, 2011.

45. Tanaka Y, Slitt AL, Leazer TM, Maher JM and Klaassen CD Tissue distribution and hormonal regulation of the breast cancer resistance protein (Bcrp/Abcg2) in rats and mice. Biochem Biophys Res Commun 326: 181-187, 2005.

46. Cui YJ, Cheng X, Weaver YM and Klaassen CD: Tissue distribution, gender-divergent expression, ontogeny, and chemical induction of multidrug resistance transporter genes (Mdrla, Mdr1b, Mdr2) in mice. Drug Metab Dispos 37: 203-210, 2009.

47. Prevoo B, Miller DS, van de Water FM, Wever KE, Russel FG, Flik G and Masereeuw R: Rapid, nongenomic stimulation of multidrug resistance protein 2 (Mrp2) activity by glucocorticoids in renal proximal tubule. J Pharmacol Exp Ther 338: 362-371, 2011.

48. Bridges CC, Joshee L, van den Heuvel JJ, Russel FG and Zalups RK: Glutathione status and the renal elimination of inorganic mercury in the Mrp2(-/-) mouse. PLoS One 8: e73559, 2013.

49. El-Sheikh AA, Koenderink JB, Wouterse AC, van den Broek PH, Verweij VG, Masereeuw R and Russel FG: Renal glucuronidation and multidrug resistance protein $2-/$ multidrug resistance protein 4-mediated efflux of mycophenolic acid: Interaction with cyclosporine and tacrolimus. Transl Res 164: 46-56, 2014. 
50. Maher JM, Slitt AL, Cherrington NJ, Cheng X and Klaassen CD Tissue distribution and hepatic and renal ontogeny of the multidrug resistance-associated protein (Mrp) family in mice. Drug Metab Dispos 33: 947-955, 2005.

51. Staud F, Cerveny L, Ahmadimoghaddam D and Ceckova M: Multidrug and toxin extrusion proteins (MATE/SLC47); role in pharmacokinetics. Int J Biochem Cell Biol 45: 2007-2011, 2013.
52. Muller F, König J, Hoier E, Mandery K and Fromm MF: Role of organic cation transporter OCT2 and multidrug and toxin extrusion proteins MATE1 and MATE2-K for transport and drug interactions of the antiviral lamivudine. Biochem Pharmacol 86: 808-815, 2013. 